\title{
ALL-CERAMIC AND PORCELAIN-FUSED-TO-METAL FIXED PARTIAL DENTURES: A COMPARATIVE STUDY BY 2D FINITE ELEMENT ANALYSES
}

\author{
Andréia Barreira MOTTA ${ }^{1}$, Luiz Carlos PEREIRA ${ }^{2}$, Andréia R.C.C da CUNHA ${ }^{3}$
}

\begin{abstract}
1- DDS, MSc in Oral Rehabilitation São Paulo University (FOB), PhD, Graduate student of Biomaterials, Metallurgy and Materials Engineering Program, Federal University of Rio de Janeiro, PEMM/COPPE/UFRJ, and Assistant Professor in Prosthesis and Dental Materials Department, Federal University of Rio de Janeiro.

2- MSc, DSc and Associate Professor, Metallurgy and Materials Engineering Program, Federal University of Rio de Janeiro, PEMM/COPPE/ UFRJ.

3- DDS, MSc in Metallurgy and Materials Engineering, Federal University of Rio de Janeiro, PEMM/COPPE/UFRJ, and Assistant Professor in Prosthesis and Dental Materials Department, Rio de Janeiro State University.
\end{abstract}

Corresponding address: Andréa Barreira Motta - Metallurgy and Materials Engineering Program, Federal University of Rio de Janeiro, PEMM/COPPE/UFRJ, Cid. Universitária-Centro de Tecnologia-Bloco F, sala F-210, Ilha do Fundão, Postal Code 68505, Zip 21941-970, Rio de Janeiro, RJ, Brazil. phone: 5521 2562-8792, Fax: 5521 3325-2396, amotta@metalmat.ufrj.br.

Received: August 22, 2006 - Modification: April 20, 2007 - Accepted: July 13, 2007

\begin{abstract}
A

11-ceramic fixed partial dentures (FPDs) have an esthetic approach for oral rehabilitation. However, metal-ceramic FPDs are best indicated in the posterior area where the follow-up studies found a lower failure rate. This $2 \mathrm{D}$ finite element study compared the stress distribution on 3-unit all-ceramic and metal-ceramic FPDs and identified the areas of major risk of failure. Three FPD models were designed: (1) metal-ceramic FPD; (2) All-ceramic FPD with the veneering porcelain on the occlusal and cervical surface of the abutment tooth; (3) All-ceramic FPD with the veneering porcelain only on the occlusal surface. A $100 \mathrm{~N}$ load was applied in an area of $0.5 \mathrm{~mm}^{2}$ on the working cusps, following these simulations: (1) on the abutment teeth and the pontic; (2) only on the abutment teeth; and (3) only on the pontic. Relative to the maximum stress values found for the physiological load, all-ceramic FPD with only occlusal veneering porcelain produced the lowest stress value (220 MPa), followed by all-ceramic FPD with cervical veneering porcelain (322 MPa) and metal-ceramic FPD (387 MPa). The stress distribution of the load applied on the abutments was significantly better compared to the other two load simulations. The highest principal stress values were low and limited in a small area for the three types of models under this load. When the load was applied on the pontic, the highest stress values appeared on the connector areas between the abutments and pontic. In conclusion, the best stress values and distribution were found for the all-ceramic FPD with the veneering porcelain only on the occlusal surface. However, in under clinical conditions, fatigue conditions and restoration defects must be considered.
\end{abstract}

UNITERMS: All-ceramic; Porcelain-fused-to-metal; Fixed partial dentures; Finite element analyses.

\section{INTRODUCTION}

In spite of the increase in the use of all-ceramic fixed partial dentures (FPDs), metal-ceramic systems continue to be used due to their clinical longevity and biocompatibility ${ }^{17}$. This kind of prosthesis is used mainly when a large number of teeth should be replaced. Advantages of metal-ceramic FPDs lie on their predictable structural performance, versatility and cost. The advantages of all-ceramic FPD are the improved esthetics and lower allergenic potential of the ceramic materials used as infrastructure ${ }^{26}$.

Although manufacturers routinely advertise all-ceramic systems as a viable option for anterior and posterior FPDs, there are few clinical studies to support these claims. Olsson, et al. ${ }^{16}(2003)$ have reported that $91 \%$ and $83 \%$ of In-Ceram alumina short-spam FPDs had survived after 5 years and 10 years, respectively, and that $6.7 \%$ fractures in a group of sixty had occurred within 12 months for Empress ${ }^{\circledR} 2$ three-unit anterior and posterior FPDs ${ }^{24}$. On the other hand, for metalceramic FPDs the survival rates found by Karlsson ${ }^{7}$ (1986) revealed a $93 \%$ success rate in a 10 -year period, while Palmqvist and $\mathrm{Swartz}^{18}(1993)$ reported a $79 \%$ success rate over an 1823-year period. In a review of FPDs failures on the past 50 years, Goodacre, et al. ${ }^{2}$ (2003) found that the porcelain fracture was the main factor for failure. The decrease in FPD survival rate after 10 years may be a result of material fatigue $e^{1,27,28,30}$ and/or a combination of biologic and biomechanical factors ${ }^{19,25}$. 
The failure rate of three-unit ceramic FPDs in the connector area has been reported to be relatively high, especially when those connectors are sharp ${ }^{8,12}$. If the connector design is altered in maximum tensile regions, the stress distribution pattern can be changed to improve the survival rate of threeunit FPDs ${ }^{13,14}$

Johanson, et $\mathrm{al}^{5}{ }^{5}$ (2000) recorded the dimensions of the metal infrastructure of metal-ceramic restorations under fabrication in dental laboratories. They analyzed 115 FPDs and found that the vertical dimensions of the connectors were greater in the anterior region (mean $4.4 \mathrm{~mm}$ ) than in the posterior region (mean $3.6 \mathrm{~mm}$ ). The results of this study contradicted this theoretical recommendation: in the posterior area, the vertical dimension is considered more important because the resultant occlusal load is along the long axis of the tooth; and in the anterior area, the horizontal dimension is more important since the anterior teeth are submitted more frequently to palato-buccal load direction. These findings are probably attributed to anatomical features. The dental technicians stated that they always tried to optimize the connector dimensions, but the space between the abutment, pontic and gingiva was the most determining factor.

The prediction of the survival rate for FPDs can be obtained by well-designed clinical studies. However, it is difficult to standardize the denture designs to ensure realistic estimates of the survival time as a function of shape parameters. Model tests with actual specimens fabricated with tooth anatomic configuration may be a useful tool for the identification of the FPD behavior ${ }^{9,10}$.

Although FPD is broadly used in oral rehabilitation, there is a small number of FPD studies using FE analysis. In addition, they address different aspects. Romeed, et al. ${ }^{22}$ (2004) analyzed the mechanical behavior of three FPD designs. The results indicated that the displacement and maximum principal stress in three-unit FPDs with the abutment teeth in both extremities of the prosthesis were substantially less than those in the two-unit cantilever FPDs. The highest values for maximum principal stress in the cantilever FPDs were found within the connector between the pontic and the retainer.

Kamposiora, et al. ${ }^{6}$ (1996) used FEA to study levels and distribution patterns of stress within three-unit FPDs constructed with different materials (Type III gold alloy, Dicor and In-Ceram) and with different connector heights $(3.0 \mathrm{~mm}$ and $4.0 \mathrm{~mm}$ ). The $10 \mathrm{MPa}$ load was centrally applied at the pontic area. The highest values of von Mises stresses were concentrated within the connectors; the greatest stresses occurred at the axial location of the connector. Stresses were $40 \%$ to $50 \%$ lower for $4.0 \mathrm{~mm}$ connectors. The stress values within In-Ceram models were lower than the values found for the other two materials. The stress values represented a lower percentage of the ultimate strength of the material.

Rapelli, et al. ${ }^{20}$ (2005) investigated 3-dimensional stress and strain distribution produced in a three-unit fiber-reinforced composite inlay FPD. The load was vertically and laterally applied at the center of the pontic area. The maximum values of stress were localized in the connector areas. When a vertical load was applied, stresses on the prepared teeth were concentrated at the cervical margin of the abutment preparation.

The purpose of this study was to investigate the stress distribution in all-ceramic and metal-ceramic FPDs designed with different geometries and submitted to different loading conditions by using the finite element analysis. The hypothesis is that the loading condition is more significant than the prosthesis design.

\section{MATERIALAND METHODS}

A caliper rule was used to measure all external diameters of the reference natural teeth (mandibular second premolar and second molar, approved in $06 / 28 / 2005$ by the Ethics in Research Committee, CEP/UFRJ, MEMO\#657/05, 105/5). The teeth internal structures were measured using X-rays images. Those measures were used to design the sound structures of both abutments. Afterwards, dental preparations were done on each tooth using the AutoCad program (2004 version; Autodesk Inc., Neuchatel, Switzerland) as specified by Shillinburg, et al. ${ }^{23}$ (1988). All the specific parts, infrastructures (metal or ceramic), veneering porcelain, cement and the pontic element (replacing the lost mandibular first molar), were designed with specific dimensions to generate different Fixed Partial Denture (FPD) models, as described below:

a) Metal-ceramic FPD with veneering porcelain on both occlusal and cervical surface in the pontic area (Metal-ceramic FPD, Figure 1-A).
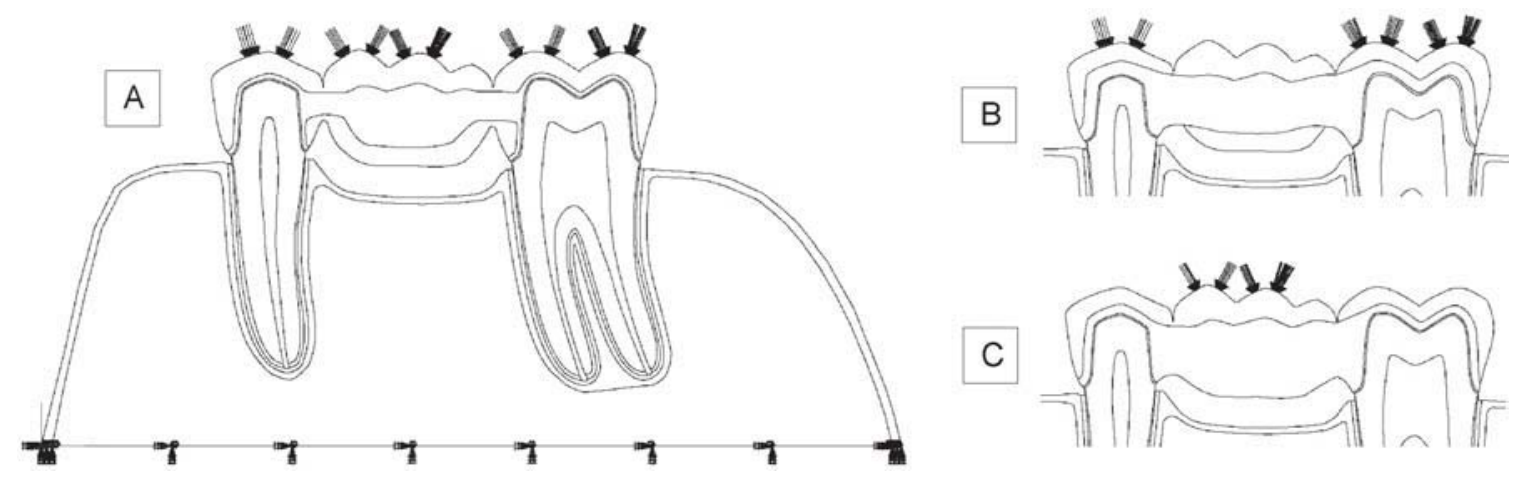

FIGURE 1- (A) Metal-ceramic FPD. The boundary conditions used for all models and the load applied distributed on all teeth (physiological load); (B) All-ceramic-OC FPD. Load applied only on abutment teeth and (C) All-ceramic-O FPD. Load applied only on the pontic 
b) All-ceramic FPD with veneering porcelain on both occlusal and cervical surface in the pontic area (all-ceramicOC FPD, Figure 1-B);

c) All-ceramic FPD with veneering porcelain on occlusal surface in the pontic area (all-ceramic-O FPD, Figure 1-C);

A 120-degree chamfer finishing line and a total axial taper of 6 degrees per abutment were used for the abutment teeth. The periodontal ligament, compact and cancellous bone were designed according to their normal anatomy ${ }^{21}$. Each part was exported to a finite element analysis program (ABAQUS CAE 6.5 version; Hibbitt, Karlsson and Sorensen Inc., Pawtucket, RI, USA). All parts were considered homogenous and isotropic. The elastic properties (Elasticity modulus and Poisson's ratios) are presented in Table 1,4,11,21,29. Regarding the boundary conditions, the encastre was always positioned at the base of the model to prevent rotation and translation.

A $100 \mathrm{~N}$ compressive load was applied to a $0.5-\mathrm{mm}^{2}$ area, described by Okeson ${ }^{15}$ (2003) as a real contact area found in most evaluated patients. The site of load application differs for each analysis: (case a) - distributed in all working cusps: physiological load (Figure 1-A); (case b) - applied only on the abutment teeth (Figure 1-B); (case c) -applied only on the pontic (Figure 1-C).

The 2D model mesh had four-node-quadrilateral elements, and its size differs for each part according to the specific needs to obtain less distortion.

The results were represented by maximum stresses tables and figures. The maximum tensile stresses are of particular interest in this study, as they have a higher potential to cause damage to FPD materials and dental tissues.

\section{RESULTS}

Figures 2 to 4 show the stress contour values resulting from an applied load of $100 \mathrm{~N}$ for all the models. The patterns of stresses distribution were similar for all models under the same loading condition. Under the physiological load (Figure $2)$, the highest principal stresses occurred on the cervical region of mesial and distal connectors and the infrastructure's cervical portion of the pontic. Relative to the model design and the restorative material, all-ceramic FPDs with only occlusal veneering porcelain produced the lowest stress value (220 MPa, Figure 2-C), followed by all-ceramic with cervical veneering porcelain (322 MPa, Figure 2-B) and metal-ceramic FPD (387 MPa, Figure 2-A).

The resulting stress distribution of the load applied on the abutments was significantly different compared to the other loading conditions (Figure 3 ). The highest values of tensile stress were found at the occlusal region of both connectors. Moreover, the highest principal stresses were lower and limited to a small area for the three models under this load. The lowest stress was verified on the metal-ceramic model (194 MPa).

When the loads were applied to the pontic (Figure 4), the highest stress values appeared on the connector. Stress distribution was similar to the models submitted to physiological load, but the stress values were higher and the tensile stress also extended to metal or ceramic infrastructure. The highest stress value was found for all-ceramic FPD with cervical veneering porcelain $(569 \mathrm{MPa})$, indicating an increasing risk of failure.

Models with cervical veneering porcelain revealed higher stress on the veneering porcelain/infrastructure interface of the pontic for the physiological and pontic loads.

Others small areas of high stress concentration were identified in proximal and marginal regions of the abutments. The highest tensile stress values found for each model are presented in Table 2.

\section{DISCUSSION}

The outcomes of the present study showed a different stress distribution depending on load configuration. A maximum bending stress in the FPD is induced when the load is applied at the central part of the pontic. The pontic central load position represents the worst loading condition based

TABLE 1- Mechanical properties of each tooth part

\section{Material}

Dentin (Toparli, et al. $\left.{ }^{29}, 2002\right)$

Cement (Toparli, et al. ${ }^{29}, 2002$ )

Pulp (Rees and Hammadeh ${ }^{21}$, 2004)

Periodontal Ligament (Rees and Hammadeh ${ }^{21}$, 2004)

Cancellous Bone (Rees and Hammadeh ${ }^{21}$, 2004)

Compact Bone (Toparli, et al., ${ }^{29}$ 2002)

Veneering Porcelain (Ibrahim, et al. ${ }^{3}$, 2004)

Infrastructure (Ni-Cr) (Toparli, et al. $\left.{ }^{29}, 2002\right)$

Infrastructure (In-Ceram) (Imanishi, et al. ${ }^{4}, 2003$ )

Cement Zinc Phosphate (Lanza, et al. ${ }^{11}$, 2005)

Cement Panavia (Imanishi, et al. ${ }^{4}, 2003$ )
Elasticity Modulus (E) (MPa)

Poisson's ratio (v)

$\begin{array}{ll}18600 & 0.31 \\ 18600 & 0.31 \\ 2.07 & 0.45 \\ 50 & 0.49 \\ 345 & 0.3 \\ 13800 & 0.26 \\ 68900 & 0.28 \\ 205000 & 0.33 \\ 269000 & 0.3 \\ 13720 & 0.35 \\ 4040 & 0.35\end{array}$


on the biomechanical principles and is always avoided by the dentists. Unfortunately most FE analyzes that have already been done used this load condition. According to this load configuration, the maximum tensile stress is always concentrated at the inferior connector region and the maximum compressive stress occurred at the occlusal embrasure, as illustrated in the presented study in Figure 4. The same results were found by Oh, et al. ${ }^{13}$ (2002). They analyzed the influence of connector design on fracture probability of ceramic FPD, using 3D FEA. All connectors were $4 \mathrm{~mm}$ in height and $5 \mathrm{~mm}$ in width but with different radii of curvature at the gingival embrasure: $0.45 \mathrm{~mm}$ and $0.25 \mathrm{~mm}$. They applied a $100 \mathrm{~N}$ load at the central fossa of the pontic. Peak compressive stresses occurred at the occlusal embrasure, and peak tensile stresses developed at the gingival embrasure, either at the center or at a position shifted slightly buccally. The smaller radii of curvature revealed a higher peak tensile stress $(21 \mathrm{MPa})$ than the other model (16.1 MPa).

Rapelli, et al. ${ }^{20}$ (2005) also found a stress concentration at the connector regions when a $196 \mathrm{~N}$ central load was applied to the pontic. They analyzed a 3D model and the stress values were calculated on the outer and inner surfaces of a fiberreinforced composite inlay FPD.

Kamposiora, et al. ${ }^{6}$ (1996) analyzed the stress distribution in In-Ceram, gold and Dicor FPDs. They found much lower stresses in In-Ceram FPDs, and concluded that the In-Ceram FPDs would be the most successful type of restoration. Conversely, in the present study the highest stress values were found for all-ceramic FPD with central pontic load. Comparing all models and loading conditions, in the model all-ceramic FPD the stress values were smaller for the pontic and physiological load and when the load was applied only on the abutment teeth the smallest stress was found for the metal-ceramic FPD model.

The load distributed on all working cusps showed a stress distribution quite similar to that of the pontic load, but with a smaller value of maximum stress. When the load was positioned only on the abutment teeth, the results showed that the stress patterns changed and the highest probability of failure would occur near the upper connector area.

As ceramic materials are very susceptible to failure under tensile loading, all-ceramic bridges require even more stringent mechanical properties than those needed for Metal-ceramic FPDs. According to some studies ${ }^{8,12,13,14,27}$, zirconia-based ceramics are the most appropriate to withstand the high tensile stress that occur on multi-unit bridges. In metal-ceramic FPDs the metal infrastructure provides the strength to resist to occlusal forces. Romeed, et al. ${ }^{22}$ (2004) stated that it is
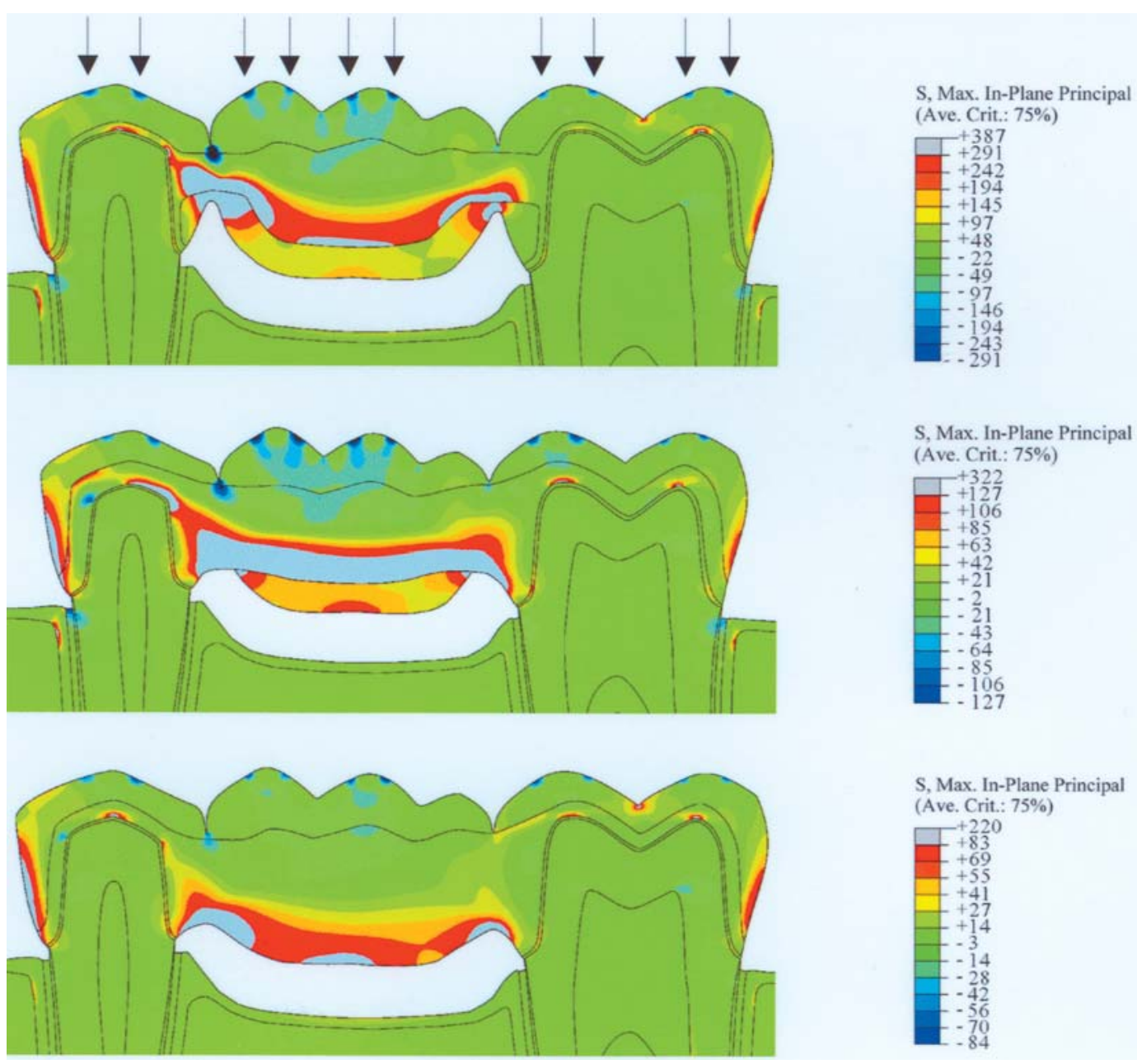

S, Max. In-Plane Principal

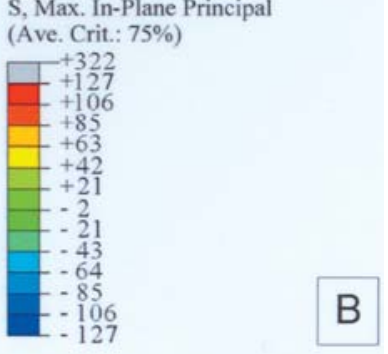

S, Max. In-Plane Principal

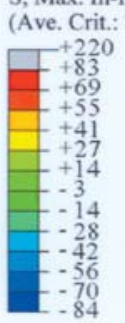

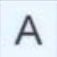

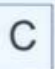

FIGURE 2- Stress distribution found when a physiological load was applied. Models: (A) Metal-ceramic FPD; (B) All-ceramicOC FPD; (C) All-ceramic-O FPD 
necessary to ensure that the highest value of principal stress in all materials was less than the relevant critical value to rule out any possibility of material failure.

Oh, et al. ${ }^{13}$ (2002) stated that once the loads to failure of prostheses are determined, these data can be applied in mathematical equations to analyze the characteristic strength of the restorations. Higher or lower load values would only change the magnitude of stress but not the distribution pattern $^{20}$. However, if the load configuration is changed the stress distribution also changes.

The present study and all researches cited were undertaken with monotonic load. The material will fail when the maximum local stress reaches the ultimate strength of the material. However, clinically, the loads are cyclic and then fatigue failure criterion must be used. Under a fatigue approach a subcritical crack growth must be considered in the regions submitted to maximum stress ${ }^{1,30}$. In some cases, the crack growth is so slow that other factors will lead to failure rather than the load. The FE stress values have to be carefully used to establish the fracture criteria or the failure of FE models. In fact, the load applied on the pontic region does not simulate the clinic situation. Studies using this load configuration have overestimated the connector regions as having the highest probability of failures.

Notwithstanding the sophistication of the FE analyses,
Romeed, et al..$^{22}$ (2004) believes that the analyses undergoes a number of limitations: materials were assumed to be isotropic, homogeneous and linear elastic, despite the anisotropic nature of some structures and the presence of voids or cracks. However, the FE analyses were considered appropriate, given that the main goal of the investigation was to compare the biomechanical behavior of the FPDs rather than report absolute values for displacements and maximum principal stresses.

\section{CONCLUSIONS}

Within the limitation of this 2D FE study, the following conclusions were drawn:

1- There is a significant change on stress distribution and values when the load configuration is changed.

2- The best loading condition for the three models was found when the load was applied only on the abutment teeth.

3- The smallest maximum principal stress value was found in the metal-ceramic FPD when the load was applied only on the abutment teeth.
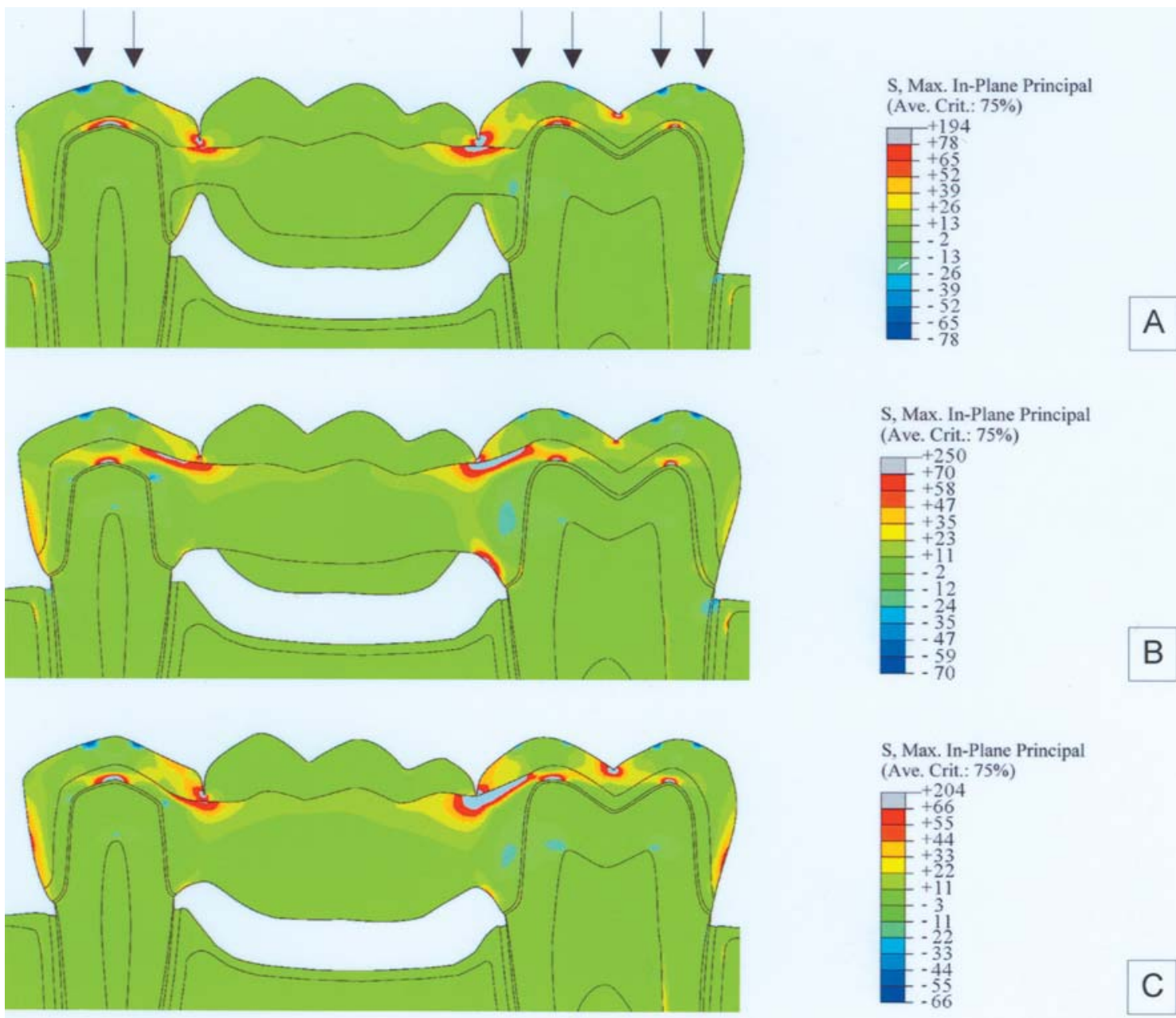

FIGURE 3- Stress distribution found when the load was applied only on the abutment teeth. Models: (A) Metal-ceramic FPD; (B) All-ceramic-OC FPD; (C) All-ceramic-O FPD 
TABLE 2- Maximum stress values for each model with different loading conditions

All-Ceramic-OC

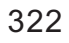

250

569

Pontic load
All-Ceramic-O

Metal-ceramic FPD

\begin{tabular}{llll} 
Physiological load & 322 & 220 & 387 \\
Abutment load & 250 & 204 & 194 \\
Pontic load & 569 & 408 & 449 \\
\hline
\end{tabular}

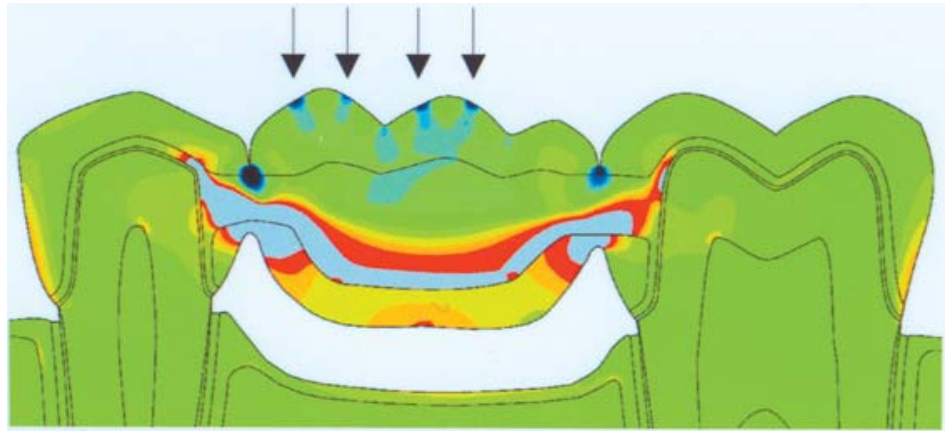

S, Max. In-Plane Principal (Ave. Crit.: $75 \%$ )
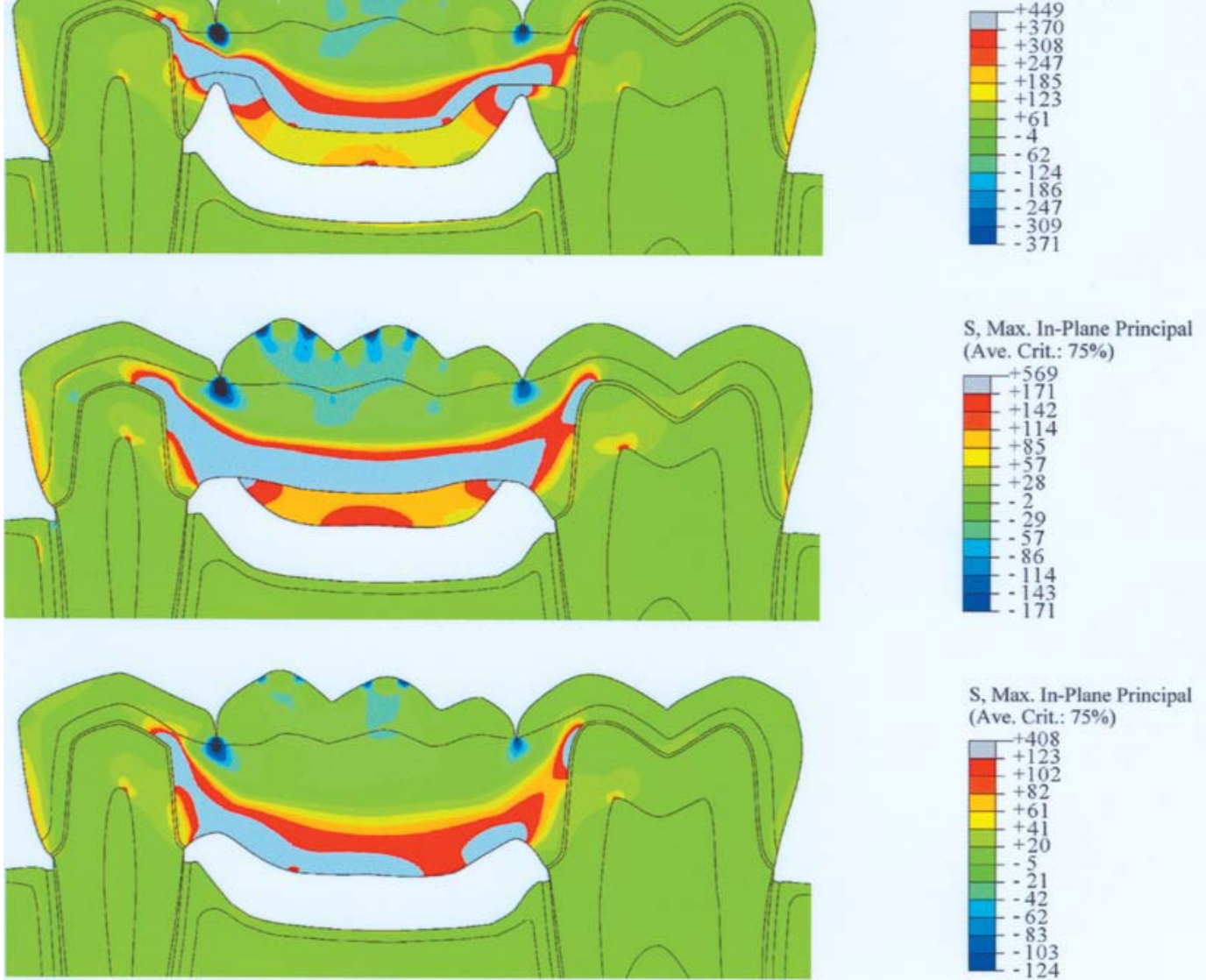

FIGURE 4- Stress distribution found when the load was applied only on the pontic. Models: (A) Metal-ceramic FPD; (B) Allceramic-OC FPD; (C) All-ceramic-O FPD

\section{ACKNOWLEDGEMENT}

The authors acknowledge the financial support by the Brazilian National Research Council (CNPq) and Telmo Roberto Strohaecker, Gabriel Tarnowsky, Fernando Pereira Duda and Bruno Reis Antunes for their help in problem solutions for model creation and analyses.

\section{REFERENCES}

1- Bradt RC, Evans AG, Hasselman DPH, Lange FF. Fracture mechanics of ceramics: microstructure, methods, design, and fatigue. Plenum Press; 1986.
2- Goodacre JC, Bernal G, Rungcharassaeng K, Kan JYK. Clinical complications in fixed prosthodontics. J Prosthet Dent. 2003;90(2):3141.

3- Ibrahim A, Sertgöz A, Ekici B. Influence of occlusal forces on stress distribution in preloaded dental implant screws. J Prosthet Dent. 2004;91:319-25.

4- Imanishi A, Nakamura T, Ohyama T, Nakamura T. 3-D Finite element analysis of all-ceramic posterior crowns. J Oral Rehabil. 2003;30(8):818-22.

5- Johanson M, Mosharraf S, Karlsson S, Carlsson GE. A dental laboratory study of the dimensions of metal frameworks for fixed partial dentures. Eur J Prosthodont Restor Dent. 2000;8(2):75-8. 
6- Kamposiora P, Papavasiliou G, Bayne SC, Felton DA. Stress concentration in all-ceramic posterior fixed partial dentures. Quintessence Int. 1996;27(10):701-6.

7- Karlsson S. A clinical evaluation of fixed bridges, 10 years following insertion. J Oral Rehabil. 1986;13(5):423-32.

8- Kelly JR, Tesk JA, Sorensen JA. Failure of all-ceramic fixed partial dentures in vitro and in vivo: analysis and modeling. J Dent Res. $1995 ; 74(6): 1253-8$

9- Kern M, Douglas WH, Fechting T, Strub JR, DeLong R. Fracture strength of all-porcelain, resin-bonded bridges after testing in an artificial oral environment. J Dent. 1993;21(2):117-21.

10- Koutayas SO, Kern M, Ferraresso F, Strub JR. Influence of design and mode of loading on the fracture strength of all-ceramic resinbonded fixed partial dentures: an in vitro study in a dual-axis chewing simulator. J Prosthet Dent. 2000;83(5):540-7.

11 - Lanza A, Aversa R, Rengo S, Apicella D., Apicella A. 3D FEA of cemented steel, glass and carbon posts in a maxillary incisor. Dent Mat. 2005;21(8):709-15.

12 - Lüthy H, Filser F, Loeffel O, Schumacher M, Gauckler LJ, Hammerle $\mathrm{CH}$. Strength and reliability of four-unit all-ceramic posterior bridges. Dent Mat. 2005;21(10):930-7.

13- Oh W, Götzen N, Anusavice KJ. Influence of connector design on fracture probability of ceramic fixed-partial dentures. J Dent Res. $2002 ; 81(9): 623-7$

14- Oh W, Anusavice KJ. Effect of connector design on the fracture resistance of all-ceramic fixed partial dentures. J Prosthet Dent. 2002;87(5):536-42.

15 - Okeson, JP. Management of temporomandibular disorders and occlusion. 5th ed. St. Louis: Mosby; 2003

16- Olsson KG, Furst B, Andersson B, Carlsson GE. A long-term retrospective and clinical follow-up study of In-Ceram Alumina FPDs. Int J Prosthodont. 2003;16(2):150-6.

17- Özcan M. Fracture reasons in ceramic-fused-to-metal restorations. J Oral Rehabil. 2003;30(3):265-9

18 - Palmqvist S, Swartz B. Artificial crowns and fixed partial dentures 18 to 23 years after placement. Int J Prosthodont. 1993;6(3):279-85.

19- Randow K, Glantz PO, Zoger B. Technical failures and some related clinical complications in extensive fixed prosthodontics. An epidemiological study of long-term clinical quality, Acta Odontol Scand. 1986;44:241-55.

20 - Rappelli G, Scalise L, Procaccini M, Tomasini EP. Stress distribution in fiber-reinforced inlay fixed partial dentures. J Prosthet Dent. 2005;93(5):425-32.

21 - Rees JS, Hammadeh M. Undermining of enamel as a mechanism of abfraction lesion formation: a finite element study. Eur J Oral Sci. 2004;112(4):347-52.

22 - Romeed SA, Fok SL, Wilson NHF. Finite element analysis of fixed partial denture replacement. J Oral Rehabil. 2004;31(12):1208-17.

23- Shillinburg HT, Hobo S, Whitsett LD, Jacobi R, Brackett SE Fundamentals of fixed prosthodontics, 3rd ed. Quintessence Publishing; 1997.

24- Sorensen JA, Kang SK, Torres TJ, Knode H. In-Ceram fixed partial dentures: three-year clinical trial results. J Calif Dent Assoc. 1998;26(3):207-14
25- Strub JR, Stiffler S, Schärer P. Causes of failure following oral rehabilitation: biological versus technical factors. Quintessence Int. 1988;19(3):215-22.

26- Studart AR, Filser F, Kocher P, Lüthy H, Gauckler LJ. Cyclic fatigue in water of veneer-framework composites for all-ceramic dental bridges. Dent Mat. 2007;23(2):177-85.

27-Sundh A, Molin M, Sjorgen G. Fracture resistance of yttrium oxide partially-stabilized zirconia all-ceramic bridges after veneering and mechanical fatigue testing. Dent Mat. 2005;21:476-82.

28 - Suresh S. Fatigue crack growth in brittle solids. In: Suresh S, editors. Fatigue of materials, 2nd ed. Cambridge University Press; 1998.

29- Toparli M, Aykul H, Aksoy T. Stress distribution associated with loaded acrylic-metal-cement crowns by using finite element method. J Oral Rehabil. 2002;29(11):1108-14

30- Tsuji K, Iwase K, Ando K. An investigation into the location of crack initiation sites in alumina, polycarbonate and mild steel. Fatigue Fract Engng Mater Struct 1999; 22:509-17. 